\title{
Establishment of perennial legume species in drought-prone, North and South Island sites
}

\author{
G.B. DOUGLAS ${ }^{1}$, B.J. WILLS ${ }^{2}$, H.N. PRYOR ${ }^{3}$, A.G. FOOTE ${ }^{1}$ and K.D. TRAINOR ${ }^{2}$ \\ ${ }^{1}$ AgResearch Grasslands, Private Bag 11008, Palmerston North \\ ${ }^{2}$ AgResearch, PO Box 228, Alexandra \\ ${ }^{3}$ AgResearch Invermay, Private Bag 50034, Mosgiel
}

\begin{abstract}
The establishment from seed of 8 perennial legumes was investigated in 3 trials in drought-prone regions. Two trials, in central Hawke's Bay, aimed to determine the extent of establishment of 6 test species (Astragalus cicer, Coronilla varia, Dorycnium hirsutum, Dorycnium pentaphyllum, Lotus corniculatus, Lotus tenuis) and 2 standard species (Medicago sativa, Trifolium repens). The third trial, in Central Otago, aimed to identify the most effective strain of Rhizobium loti for nodulating $D$. hirsutum in the field. In Hawke's Bay, establishment of all species was satisfactory. Seedling emergence ranged from $0.2 \%$ (T. repens) to $25 \%$ (A. cicer, C. varia, D. hirsutum), but emergence levels for all species varied between trials. Herbage yields of $A$. cicer (4 t DM/ha), $C$. varia (3 t DM/ha) and L. tenuis (3.7 t DM/ha) were relatively high, and they could have potential as forages. Inoculation of seed of D. hirsutum with $R$. loti strain ICC 211 resulted in $60 \%$ of seedlings being nodulated, compared with $25 \%$ where strain ICC224 was used. Foliage weights of all plants inoculated with strain ICC211 (154 mg) were higher than those inoculated with strain ICC224 (52 mg). Strain ICC211 is recommended for inoculating $D$. hirsutum.
\end{abstract}

Keywords: dryland legumes, nodulation, plant establishment, revegetation

\section{Introduction}

Perennial legume species such as Astragalus cicer, Coronilla varia, Dorycnium spp. and Lotus spp. are potentially useful for revegetating seasonally dry areas in the North (Rys et al. 1988; Douglas \& Foote 1994) and South (Chapman et al. 1989; Wills et al. 1989) Islands, and as potential forage sources in these environments. The satisfactory to excellent survival and growth of these species in spaced-plant evaluations has created an interest in their potential to establish successfully from sowing.

Few sowing trials have been conducted recently. At four tussock grassland sites in the South Island, $C$. varia oversown in the spring failed to emerge, or had very low seedling densities $\left(<1\right.$ per $\left.\mathrm{m}^{2}\right)$ (Lowther \& Patrick 1992). Emergence of Lotus corniculatus cv. Maitland was $12-22 \%$, but there was a virtual nodulation failure at all sites, and plant survival after 14 months was negligible. In Central Otago, initial establishment of Dorycnium hirsutum (PN 1059) drilled in spring, was almost as good as that of lines of $L$. corniculatus and $L$. tenuis, and slightly better than that of Medicago sativa cv. WL318 (Wills et al. 1989). Emergence of $D$. hirsutum and D. pentaphyllum in the North Island has been less than $35 \%$ of viable seed sown, but survival has been moderate $(35 \%)$ to high $(90 \%)$ (Douglas \& Foote 1994).

Nodulation of $D$. hirsutum under field conditions has been highly variable, particularly in the South Island. Brockwell \& Neal-Smith (1966) concluded that $D$. hirsutum possessed a wide symbiotic range as it fixed nitrogen with a diverse range of isolates selected from the Loteae tribe. In New Zealand, rhizobia strains for $L$. corniculatus have been moderately effective in nodulating D. hirsutum (Wills et al. 1989), strain SU343 (=ICC224) currently being used in the South Island. However, Charlton (1981) found that strain PDD2213 (=ICC211) was superior to SU343 in enhancing early seedling growth, which could be important for the reported need to allow extended establishment periods for D. hirsutum (Wills et al. 1989). Strain PDD2213 has been used to nodulate $D$. hirsutum in the North Island (Douglas \& Foote 1994), but its effectiveness in the field has not been compared with that of other strains.

This paper reports results from 3 establishment studies involving perennial legume species. The North Island trials (Trials 1 and 2) determined seedling establishment of 8 species, while the South Island study (Trial 3) aimed to identify the most effective strain of Rhizobium loti for nodulation and symbiotic nitrogen fixation of $D$. hirsutum under field conditions.

\section{Materials and methods}

\section{Sites}

Trials 1 and 2 were conducted in central Hawke's Bay on Takapau shallow stony silt loam soil types, which are prone to summer drought and wind erosion. Annual 
rainfall in the area is $850 \mathrm{~mm}$ (35-year mean). Soils were slightly acid (soil $\mathrm{pH}$ 6.2-6.6) with low to moderate/high levels of Olsen P in Trials $1(<15 \mathrm{mg} / \mathrm{kg}$ soil) and $2(>30 \mathrm{mg} / \mathrm{kg}$ soil), respectively. Both sites were flat and resident vegetation at each site was sprayed with glyphosate $(1.1 \mathrm{~kg}$ ai $/ \mathrm{ha})$ and dicamba $(0.3 \mathrm{~kg}$ ai/ ha) 4-5 weeks before trial commencement, and trifluralin $(1.2 \mathrm{~kg} \mathrm{ai} / \mathrm{ha})$ was soil incorporated immediately before sowing.

Trial 3 was conducted on Galloway Station in Central Otago, part of the Crawford Hills (about $500 \mathrm{~m}$ asl). Annual rainfall ( 60 year mean) is $500 \mathrm{~mm}$. The soil was an Alexandra steepland brown-grey earth, and the site was very depleted, with shallow soils predominantly covered in scabweed (Raoulia spp.) and viper's bugloss (Echium vulgare). All trials were fenced to exclude rabbits.

\section{Experimental design and treatments}

The North Island trials were sown on 29 April (Trial 1) and 13 September 1995 (Trial 2), and comprised 4 randomised complete blocks with plots of $3 \times 6 \mathrm{~m}$. The seed-beds were cultivated and there were 6 test species in each trial, namely Astragalus cicer (cicer milkvetch), Coronilla varia (crownvetch), Dorycnium hirsutum (hairy dorycnium), D. pentaphyllum (prostrate dorycnium), Lotus corniculatus (birdsfoot trefoil) cv. Grasslands Goldie, and L. tenuis (narrow-leaf birdsfoot trefoil). Medicago sativa cv. Grasslands Oranga and Trifolium repens cv. Grasslands Demand were included for comparison. Seed was inoculated $\left(10^{8}\right.$ bacterial cells/ $\mathrm{ml}$ ) with specific Rhizobium strains (Douglas \& Foote 1994), coated with kaolin and methyl cellulose (sticking agent), and broadcast sown within 24 hours of inoculation at a rate equivalent to that of $8 \mathrm{~kg} / \mathrm{ha}$ of $L$. corniculatus (530 viable seeds $/ \mathrm{m}^{2}$ ). Seed was buried to $1 \mathrm{~cm}$ depth by light harrowing.

Trial 3 comprised 4 replicates of 5 treatments (2 inoculant strains $\times 2$ levels + uninoculated control) and $3 \mathrm{~m}^{2}$ plots. The ground was cultivated and standard sulphur superphosphate was applied at $250 \mathrm{~kg} / \mathrm{ha}$. Inoculated seed of Dorycnium hirsutum was sown on 13 September, 1995. Inoculants were prepared by incorporating strain ICC224 or ICC211 in prepared sterile peats. Populations of rhizobia in the peat at inoculation were $1.8 \times 10^{9}$ and $4.4 \times 10^{9}$ for ICC211 and ICC224 respectively.

Seed was inoculated with ICC224 at the stipulated rate $(10 \mathrm{~g}$ peat per $\mathrm{kg}$ seed $)$ and at 5-times this rate. Peat weights of ICC211 were adjusted to apply the same number of rhizobia per seed at inoculation as ICC224. Seed was pelleted with gum arabic and microfine lime, left to dry for 1 hour then stored at $12^{\circ} \mathrm{C}$ overnight before sowing the following day. The numbers of rhizobia per seed at inoculation were $1.8-$ $2.3 \times 10^{4}$ at the stipulated rate and $6.9-8.5 \times 10^{4}$ at the 5 -times rate.

\section{Measurements}

Trial 1: Seedlings were counted in $2 \times 0.125 \mathrm{~m}^{2}$ quadrats per plot on 30 May 1995, approximately 4 weeks after sowing. On 27 October 1995, 10 randomly selected seedlings per plot were assessed for height $(\mathrm{cm})$, vigour (1=poor to $5=$ near perfect), and presence of at least 1 nodule. Seedling number per plot was scored at the same time as 0 (absent), 1 (1-100 seedlings), or 2 (>100 seedlings).

Trial 2: Seedlings were counted as in Trial 1, on 19 October and 14 December 1995. Height, vigour and presence of nodules were determined on 20 December 1995, as described for Trial 1. Also on 20 December, seedling number per plot was scored 1 (1-20 seedlings), 2 (20-100 seedlings), or 3 (>100 seedlings), and plots with $>10 \%$ flowering were recorded. On 18 January 1996, plots were assessed for ground cover (\%), height $(\mathrm{cm})$, and extent of flowering (\%). Vigour of all swards was assessed as near perfect. Final assessments were conducted on 14 February 1996 and in addition to repeating the assessments conducted on 18 January, plots were assessed for presence of pods and herbage mass $\left(2 \times 0.125 \mathrm{~m}^{2}\right.$ quadrats per plot $)$.

Trial 3: Twenty seedlings per treatment were pegged on 28 November 1995, and harvested on 26 March, 1996. Seedling survival was assessed, and then individual seedlings were harvested and the presence of nodules determined. Foliage dry weight $\left(24 \mathrm{hrs}\right.$ at $\left.70^{\circ} \mathrm{C}\right)$ was determined for all surviving seedlings.

\section{Results}

\section{Trial 1}

All species emerged within 4 weeks of sowing, emergence ranging from $5 \%$ of viable seed sown for $A$. cicer, to $20 \%$ for $M$. sativa (Table 1). By mid spring, 5 of the 8 species had 1-100 seedlings/plot, while in some replicate plots of $L$. tenuis and $T$. repens, seedling numbers exceeded 100 /plot. M. sativa was the only species with more than 100 seedlings in all plots.

All species were less than $10 \mathrm{~cm}$ tall, except for $M$. sativa which was at least twice as high as any other species (Table 1). Seedlings of all species had slight chewing damage (vigour scores of 3-4), probably mostly from accidental grazing rather than insect pests.

Root nodules were detected on all species except $A$. cicer and C. varia (Table 1), although the extent of nodulation varied considerably between species. Nodules 
Table 1 Vegetative development of eight species oversown on 28 April 1995 in central Hawke's Bay (Trial 1).

\begin{tabular}{|c|c|c|c|c|c|}
\hline Species & $\begin{array}{c}\text { Emergence } \\
(\%) \\
30 / 5 / 95\end{array}$ & $\begin{array}{l}\text { Seedling number }{ }^{2} \\
27 / 10\end{array}$ & $\begin{array}{l}\text { Height } \\
(\mathrm{cm}) \\
27 / 10\end{array}$ & $\begin{array}{l}\text { Vigour }^{3} \\
27 / 10\end{array}$ & $\begin{array}{c}\text { Plants nodulated } \\
(\%) \\
27 / 10 / 95\end{array}$ \\
\hline Astragalus cicer & $5.5 e^{1}$ & $1.0 \mathrm{c}$ & $2.5 f$ & $3.3 \mathrm{~cd}$ & $0 d$ \\
\hline Coronilla varia & $13.8 \mathrm{bcd}$ & $1.0 \mathrm{c}$ & $2.6 f$ & $3.2 \mathrm{~cd}$ & Od \\
\hline Dorycnium hirsutum & $7.9 \mathrm{de}$ & $1.0 \mathrm{c}$ & $8.7 b$ & $3.0 \mathrm{~d}$ & $20 \mathrm{~cd}$ \\
\hline Dorycnium pentaphyllum & 11.5bcde & $1.0 \mathrm{c}$ & 4.3de & $3.6 b c$ & $50 \mathrm{~b}$ \\
\hline Lotus tenuis & 17.0ab & $1.5 b$ & $5.2 d$ & 4.0ab & $38 \mathrm{bc}$ \\
\hline Medicago sativa & $20.6 a$ & $2.0 a$ & $16.4 a$ & $3.4 \mathrm{~cd}$ & $53 b$ \\
\hline Trifolium repens & 14.9abc & 1.8ab & $3.1 \mathrm{ef}$ & $3.3 \mathrm{~cd}$ & $100 a$ \\
\hline
\end{tabular}

${ }^{1}$ figures with the same letters do not differ at the $5 \%$ significance level; ${ }^{2}$ scored $1=1-1002=>100 ;{ }^{3} 1=$ poor, $5=$ near perfect.

Table 2 Vegetative and reproductive development of eight species oversown on 13 September 1995 in central Hawke's Bay during 1995/96 (Trial 2).

\begin{tabular}{|c|c|c|c|c|c|c|c|c|c|}
\hline \multirow[t]{2}{*}{ Species } & \multicolumn{2}{|c|}{ Emergence (\%) } & \multirow{2}{*}{$\begin{array}{l}\text { Height } \\
(\mathrm{cm}) \\
14 / 2\end{array}$} & \multirow{2}{*}{$\begin{array}{c}\text { Ground } \\
\text { cover }(\%) \\
14 / 2\end{array}$} & \multicolumn{3}{|c|}{ Extent of flowering } & \multirow{2}{*}{$\begin{array}{c}\text { Pod }^{3} \\
\text { production } \\
14 / 2\end{array}$} & \multirow{2}{*}{$\begin{array}{c}\text { Herbage mass } \\
(\mathrm{kgDM} / \mathrm{ha}) \\
14 / 2 / 96\end{array}$} \\
\hline & 19/10/95 & $14 / 12$ & & & $20 / 12^{2}$ & $18 / 1$ & $14 / 2$ & & \\
\hline Astragalus cicer & $25.7 a^{1}$ & $24.7 a b$ & $52.2 b$ & $100.0 a$ & 0 & $6.3 c$ & $5.0 \mathrm{bc}$ & 2 & $3980 a$ \\
\hline Coronilla varia & $25.5 a$ & $19.2 \mathrm{~b}$ & $53.7 \mathrm{~b}$ & $100.0 \mathrm{a}$ & 0 & $5.0 \mathrm{c}$ & $5.0 \mathrm{bc}$ & 0 & $3070 \mathrm{abc}$ \\
\hline Dorycnium hirsutum & $25.1 \mathrm{a}$ & $27.0 \mathrm{a}$ & $38.1 \mathrm{c}$ & $98.8 \mathrm{a}$ & 0 & $1.3 c$ & $1.3 c$ & 0 & $2910 b c$ \\
\hline Dorycnium pentaphyllum & $20.9 a$ & $20.9 a b$ & $25.2 d$ & $96.3 a$ & 0 & $0 c$ & $0 c$ & 0 & $2040 c$ \\
\hline Lotus corniculatus & $1.3 \mathrm{c}$ & $1.5 \mathrm{~d}$ & $27.3 d$ & $65.0 \mathrm{~b}$ & 1 & $50.0 \mathrm{~b}$ & $17.5 a$ & 4 & $2720 b c$ \\
\hline Lotus tenuis & $9.2 \mathrm{~b}$ & $8.5 c$ & $43.5 c$ & $100.0 a$ & 4 & $100.0 a$ & $8.8 \mathrm{~b}$ & 4 & $3660 a b$ \\
\hline Medicago sativa & $3.9 \mathrm{bc}$ & $7.0 \mathrm{~cd}$ & $62.6 a$ & $85.0 a$ & 0 & $42.5 b$ & $16.3 a$ & 0 & $2920 b c$ \\
\hline Trifolium repens & $0.2 c$ & $0.9 d$ & $9.2 \mathrm{e}$ & $38.8 \mathrm{c}$ & 0 & $3.8 \mathrm{c}$ & $3.8 \mathrm{bc}$ & 0 & $550 d$ \\
\hline
\end{tabular}

${ }^{1}$ figures with the same letters do not differ at the $5 \%$ significance level; ${ }^{2}$ number of replicate plots with greater than $10 \%$ flowering; ${ }^{3}$ number of replicate plots with pods.

were found on all sampled seedlings of $T$. repens, and $88 \%$ of those of $L$. corniculatus. About $40-50 \%$ of seedlings of $D$. pentaphyllum, L. tenuis, and $M$. sativa were nodulated, while nodules were detected on only $20 \%$ of $D$. hirsutum seedlings.

\section{Trial 2}

Five weeks after sowing, A. cicer, C. varia and the Dorycnium spp. had 21-26\% seedling emergence (Table $2)$, at least twice the emergence $(0.2-9.2 \%)(\mathrm{P}<0.05)$ of the other 4 species (Table 2).

Emergence of all species was unchanged approximately 2 months later, in December. Seedlings of the 8 species were in near perfect condition, but root nodules were undetected. Species with consistently more than 100 seedlings per plot were A. cicer, C. varia, Dorycnium spp., and L. tenuis. L. tenuis was the only species with greater than $10 \%$ of plants flowering in all replicate plots (Table 2).

By mid January 1996, swards of $L$. tenuis were at peak flower, and $L$. corniculatus and $M$. sativa had reached approximately $50 \%$ of peak flowering (Table 2). All other species produced negligible flowers, or failed to flower (D. pentaphyllum), and this was also observed in mid February. Pods were produced by the Lotus spp. in all replicate plots, and by A. cicer in 2 plots (Table 2).

Mature plant height ranged from $10 \mathrm{~cm}$ (T. repens) to $60 \mathrm{~cm}$ (M. sativa), most species being $30-50 \mathrm{~cm}$ tall. Six of the 8 species achieved high ground cover, only plots of L. corniculatus $(65 \%)$ and $T$. repens $(40 \%)$ having significant areas of bare ground. Herbage mass ranged from $0.5 \mathrm{t} \mathrm{DM} /$ ha for $T$. repens to $4.0 \mathrm{t} \mathrm{DM} / \mathrm{ha}$ for A. cicer (Table 2), measurements for 7 of the 8 species being higher than $2.0 \mathrm{t} \mathrm{DM} / \mathrm{ha}$.

\section{Trial 3}

Seedlings failed to nodulate in the absence of inoculation (Table 3).

The percentage of seedlings nodulated was significantly $(\mathrm{P}<0.001)$ higher when seed had been inoculated with strain ICC211 than with ICC224 (60 vs 25 ; $\mathrm{SED}=5.1 \%)$. The difference between strains occurred at both inoculation levels (Strain $\mathrm{x}$ Level interaction not significant). Increasing the inoculation level significantly increased $(\mathrm{P}<0.01)$ seedling nodulation ( 34 vs 51 ; SED $=5.1 \%$ ), with the effect apparent with both strains (Table 3). 
Foliage weight of all plants inoculated with strain ICC211 was significantly higher than those inoculated with strain ICC224 (154 vs 52; SED = $14.4 \mathrm{mg}$ ). Foliage weight of nodulated plants was also significantly higher when inoculated with strain ICC211 than with strain ICC224 (239 vs 128; SED = $38.5 \mathrm{mg}$ ). There was a trend (not significant) for the DM of nodulated plants to be lower at the high inoculation rates.

\section{Discussion}

Trials 1 and 2: The results from the central Hawke's Bay studies showed that the perennial legume species established satisfactorily from seed, and therefore that their introduction could be achieved in practice. Emergence levels were similar or lower than those found in other recent establishment studies in the lower North Island. For example, emergence of $L$. corniculatus cv Grasslands Goldie on a drought-prone silt/sand loam was 8\% (Douglas \& Foote 1994) while the emergence of the American cultivar Granger, was $33-45 \%$ on other sandy and silty soil types (Douglas et al. 1990). Emergence of D. pentaphyllum in our trials (11-20\%) was lower than found previously (31\%; Douglas \& Foote 1994).

Other North Island data for C. varia are unavailable, but establishment of this species was considerably more successful than in recent South Island studies, where it failed to establish at 3 of 4 sites (Lowther \& Patrick 1992). Soil temperature was not monitored in our study although it seems that the high base temperature $\left(6.9^{\circ} \mathrm{C}\right)$ required for successful germination of $C$. varia, compared with conventional clover species (Hill \& Luck 1991), was encountered in both trials, particularly Trial 2. Emergence of $C$. varia, and also A. cicer, D. hirsutum and $D$. pentaphyllum, was $2-5$ times higher from spring (Trial 2) than autumn (Trial 1) sowing, suggesting a response to possible warmer soil temperatures.

Despite the low emergence of the Lotus spp. and $M$. sativa in Trial 2, they attained ground cover of 65 $100 \%$ and herbage yield of $2.7-3.7 \mathrm{t} \mathrm{DM} / \mathrm{ha}$ within 3 months of a spring sowing. $M$. sativa also grew well in a spaced plant evaluation of 7 perennial species on a highly fertile (Olsen $\mathrm{P}=30 \mathrm{mg} / \mathrm{kg}$ soil) flat site in eastern Hawke's Bay, where it was the highest yielding species in each of 3 successive years (Rys et al. 1988). Under lower fertility (Olsen $\mathrm{P}=15 \mathrm{mg} / \mathrm{kg}$ soil) (Rys et al. 1988), yield data were not collected, but $M$. sativa had lower plant survival than D. hirsutum and $L$. corniculatus. Experience indicated that these species were most suited to low to moderately fertile, droughtprone sites (e.g., Scott \& Charlton 1983), and it is perhaps because soil fertility was moderate to high in our studies, that clear advantages of the test species over M. sativa were unconfirmed.
Table 3 Effect of strain and inoculation level on the percentage of seedlings nodulated and foliage dry weight of Dorycnium hirsutum plants 6 months after sowing (Trial 3).

\begin{tabular}{lcccc}
\hline Strain & $\begin{array}{c}\text { Inoculation } \\
\text { level }\end{array}$ & $\begin{array}{c}\text { \% plants } \\
\text { nodulated }\end{array}$ & $\begin{array}{c}\text { Foliage dry weight (mg/plant) } \\
\text { All plants }\end{array}$ & Nodulated plants \\
\hline None 1 & 0 & 0 & 38 & - \\
ICC211 & Normal & $48.5 \mathrm{~b}$ & $157 \mathrm{a}$ & $280 \mathrm{a}$ \\
ICC211 & $x 5$ & $70.5 \mathrm{a}$ & $152 \mathrm{a}$ & $199 \mathrm{ab}$ \\
ICC224 & Normal & $19.3 \mathrm{c}$ & $58 \mathrm{~b}$ & $149 \mathrm{~b}$ \\
ICC224 & $\mathrm{x} 5$ & $30.8 \mathrm{c}$ & $47 \mathrm{~b}$ & $108 \mathrm{~b}$ \\
\hline
\end{tabular}

${ }^{1}$ not included in analysis; ${ }^{2}$ figures with the same letters do not differ at the $5 \%$ significance level.

The growth characteristics and high yield of $A$. cicer, compared to the other test species and standards, provided further evidence of the potential usefulness of this species as a legume for dry areas. Rys et al. (1988) recommended that the species should be evaluated further in New Zealand because of its high persistence and herbage yields similar to those of $L$. corniculatus and Sanguisorba minor ssp. muricata, and for 3 years (Douglas unpubl.), several lines of $A$. cicer have grown well as spaced plants in central Hawke's Bay. In the United States, the species is used for pasture, hay and conservation under dryland conditions (Townsend 1993), and a similar role is suggested for it in New Zealand.

Excluding chewing damage, the healthy, vigorous growth in both trials indicated that all species were not hindered by the frequent apparent failure to develop an effective plant host-Rhizobium symbiosis. Inoculum was effectively applied and it must therefore be concluded that post-sowing factors were responsible for the nodulation failures. The good growth of all species suggested that available soil nitrogen levels were adequate to compensate for the lack of symbiotically fixed nitrogen.

The production of pods by A. cicer and the Lotus spp. within 5 months of sowing could benefit these species by enabling earlier development of buried seed. Such a resource would increase the opportunity for continued re-establishment.

Trial 3: Inoculation is not considered to be a problem on better brown-grey and yellow-grey earth soils (Wills et al. 1989), but the results indicated clearly that nodulation failure can limit the establishment of $D$. hirsutum at low fertility. A more effective strain of rhizobia (ICC211) increased the percentage of seedlings nodulated and seedling growth. As inoculation rates were adjusted to supply similar numbers of rhizobia per seed, results were clearly attributable to strain differences 
and not to the effect of a higher population of rhizobia on the seed. No differences in seedling nodulation or plant growth on L. corniculatus were found between these 2 strains by Lowther \& Patrick (1995). The difference between the response of the 2 strains on $D$. hirsutum and L. corniculatus confirms the early caution of Chatel \& Greenwood (1973) that, in view of the complexity of the nodulation process, each Rhizobiumhost plant symbiosis be studied separately. It is also clear from the results that inoculation rates higher than those normally stipulated should be recommended to maximise establishment. The trend for DM to be lower at the 5-times inoculation rate may be attributed to the higher number of plants in the treatment and consequent inter-plant competition.

The magnitude of the increase in growth of nodulated plants $(87 \%)$ has important implications for improving the establishment of $D$. hirsutum under difficult environmental conditions where it has potential (Wills et al. 1989). The resulting improvement in seedling growth may also decrease the need for extended establishment periods identified by Wills et al. (1989). Our results have been obtained in the first growing season and it is therefore unknown if the improved symbiotic nitrogen fixation and growth will extend into further years.

These results provide sufficient field evidence to change the strain recommendation for $D$. hirsutum to ICC211. However further laboratory work is required to verify the suitability of the strain for inoculant production.

\section{ACKNOWLEDGEMENTS}

This work was funded by the Foundation for Research, Science and Technology. Land was kindly provided by Peter Catley, Keith Taylor (Hawke's Bay sites) and Andrew Preston (Central Otago site).

\section{REFERENCES}

Brockwell, J.; Neal-Smith, C.A. 1966. Effective nodulation of Hairy Canary clover Dorycnium hirsutum (L.) Ser. in DC. Australia, Canberra, A.C.T., CSIRO, Division of Plant Industry. Field Station Record 5 (1): 9-15.

Chapman, H.P.; Keoghan, J.M.; Cossens, C.G.; Allan, B.E.; Littlejohn, R.P. 1989. Promising pasture species for drought prone slopes in the South Island high country. Proceedings of the Agronomy Society of New Zealand 19: 77-84.

Charlton, J.F.L. 1981. Comparison of the effectiveness of Rhizobium strains during establishment of Lotus corniculatus in hill country. New Zealand journal of experimental agriculture 9: 173-177.

Chatel, D.L.; Greenwood, R.M. 1973. Differences between strains of Rhizobium trifolii in ability to colonize soil and plant roots in the absence of their specific host plants. Soil biology \& biochemistry 5: 809-813.

Douglas, G.B.; Foote, A.G. 1994. Establishment of perennial species useful for soil conservation and as forages. New Zealand journal of agricultural research 37: 1-9.

Douglas, G.B.; Robertson, A.G.; Chu, A.C.P.; Gordon, I.L. 1990. Establishment and growth of sheep's burnet in the lower North Island of New Zealand. New Zealand journal of agricultural research 33: 385-394.

Hill, M.J.; Luck, R. 1991. The effect of temperature on germination and seedling growth of temperate perennial pasture legumes. Australian journal of agricultural research 42: 175-189.

Lowther, W.L.; Patrick, H.N. 1992. Seedling establishment characteristics of alternative legume species in tussock grassland environments. Proceedings of the New Zealand Grassland Association 54: 111114.

Lowther, W.L.; Patrick, H.N. 1995. Rhizobium strain requirements for improved nodulation of Lotus corniculatus. Soil biology \& biochemistry 26: 721724.

Rys, G.J.; Smith, N.; Slay, M.W. 1988. Alternative forage species for Hawke's Bay. Proceedings of the Agronomy Society of New Zealand 18: 75-80.

Scott, D.; Charlton, J.F.L. 1983. Birdsfoot trefoil (Lotus corniculatus) as a potential dryland herbage legume in New Zealand. Proceedings of the New Zealand Grassland Association 44: 98-105.

Townsend, C.E. 1993. Breeding, physiology, culture, and utilization of cicer milkvetch (Astragalus cicer L.). Advances in agronomy 49: 253-308.

Wills, B.J.; Begg, J.S.C.; Foote, A.G. 1989. Dorycnium species - two new legumes with potential for dryland pasture rejuvenation and resource conservation in New Zealand. Proceedings of the New Zealand Grassland Association 50: 169-174. 
